\title{
AN EVALUATION OF THE PHYSICAL PROPERTIES OF A NEW ATRAUMATIC RESTORATIVE TREATMENT MATERIAL CONTAINING AZADIRACHTA INDICA (NEEM)
}

\author{
Divya Kumari P1, Shahnawaz Khijmatgar², Avidyuti Chowdhury33, Philippe B. Wilson', Lynch Edward5, Grootveld Martin' \\ Chitta Ranjan Chowdhury ${ }^{7}$
}

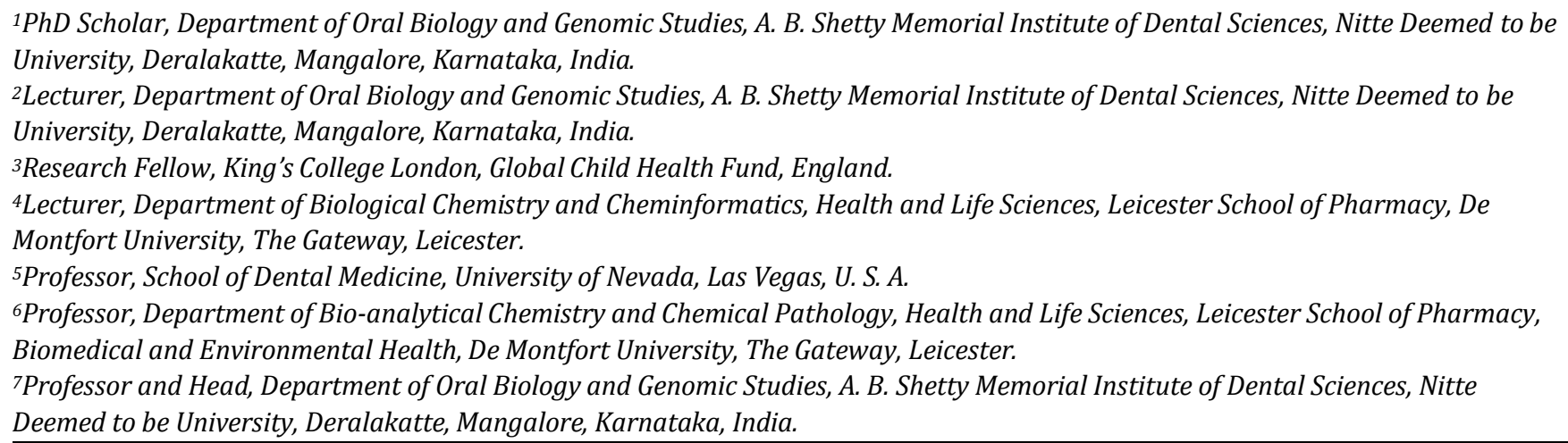
Deemed to be University, Deralakatte, Mangalore, Karnataka, India.

\section{BACKGROUND}

ABSTRACT

This in vitro experimental study investigated and compared the physical properties of three newly developed atraumatic restorative treatment materials.

\section{MATERIALS AND METHODS}

Atraumatic Restorative Treatment materials (ART) with three different compositions were prepared by varying the percentage of Azadirachta indica (Neem) extract within the materials. Micro-hardness, compressive strength, marginal adaptation to tooth structure of the atraumatic restorative treatment materials were assessed.

Statistical Analysis Used- Data was analysed using SPSS version 20 statistical software. One-Way ANOVA, Tukey's Highly Significant Difference (HSD), Scheffe's tests were conducted to assess the level of significance of differences between mean values in post-hoc testings. $\mathrm{P}<0.05$ was considered statistically significant.

Settings and Design- Samples were prepared in the Department of Oral Biology and Genomic Studies, AB Shetty Dental College and experiments were conducted in NITK, Surathkal.

\section{RESULTS}

The micro-hardness of ART-I was found to be 21.1 - 25.8 VHN, whilst ART-II showed values between 13.2 - 16.3 VHN. The compressive strengths of ART-I and II were 38.2 - 56 and 43.3 - 61 MPa respectively. The micro-hardness of the ART-III was from 35.3 - 36.4 VHN. However, the compressive strength of ART-III was 31.2 - $38 \mathrm{MPa}$. Micro-hardness was recorded as significantly high when compared between the groups $(\mathrm{P}<0.0001)$. Although, there were no significant differences in compressive strengths between the ART-I and ART-II materials (P > 0.05), the compressive strength of ART-III was significantly greater than those of the ART-I and II $(\mathrm{P}<0.05)$. No marginal gap was observed between the walls of the cavities in extracted teeth and restorative ART-II, whereas these were found when employing the ART-I and III products.

\section{CONCLUSION}

The ART-II product evaluated physical properties consistent with promising Atraumatic Restorative Treatment materials, unlike the ART-I and III.

\section{KEY WORDS}

Antibacterial Agent, ART Materials, Compressive Strength, Marginal Adaptation, Marginal Gap, Micro-Hardness, Neem.

HOW TO CITE THIS ARTICLE: Kumari DP, Khijmatgar S, Chowdhury A, et al. An evaluation of the physical properties of a new atraumatic restorative treatment material containing azadirachta indica (neem). J. Evolution Med. Dent. Sci. 2018;7(38):42014207, DOI: $10.14260 /$ jemds/2018/939

'Financial or Other Competing Interest': None.

Submission 11-08-2018, Peer Review 04-09-2018,

Acceptance 10-09-2018, Published 17-09-2018.

Corresponding Author:

Chitta Ranjan Chowdhury,

Professor and Head,

Department of Oral Biology and Genomic Studies,

A. B. Shetty Memorial Institute of Dental Sciences,

Nitte Deemed to be University, Deralakatte,

Mangalore, Karnataka, India.

E-mail:crc.ob.cod@gmail.com

DOI: $10.14260 /$ jemds $/ 2018 / 939$

\section{BACKGROUND}

Atraumatic Restorative Treatment (ART) serves a minimal interventional clinical restorative technique.[1] Indeed, its major advantage is that it requires minimal resources and can easily be used in community settings.[2,3] Hence, such materials can be considered as low-cost restorative strategies for the rapid treatment of dental caries.[4,5]

Orally, restorative materials in teeth are continuously exposed to human saliva and therefore their physical and mechanical properties are required to be viable within such a physiological environment, which has a high level of both biochemical and microbiological complexity.[6,7] There are 
various ART materials available in the market, ranging from temporary and semi-permanent to permanent alternatives. ART materials can be functionalised to have adhesive, antibacterial and fluoride anion-releasing properties. Some recent ART materials available in the market are quite durable and have the strength to withstand normal occlusal forces. Such materials have promising physical properties and most importantly fluoride releasing capacity.[8,9] Conventional glass ionomer and resin-modified glass ionomer cements have been previously employed, but these have certain shortcomings.[10-15]

The in vitro experimental present study aimed to develop a more financially-viable ART material incorporated with Neem (Ethanolic Neem extract), which has proven antibacterial activity. The objectives of the study were to determine and compare the physical properties of newlydeveloped ART materials, specifically micro-hardness, compressive strength, surface morphology and marginal adaptation using Scanning Electron Microscopy (SEM) prior and subsequent to incorporation with an ethanolic extract of Neem, a natural product with established antibacterial properties compared with conventional ART materials. $[16,17,18]$

\section{MATERIALS AND METHODS}

A total of $n=60$ cylindrical samples of ART materials (20 samples of ART-I, ART-II and ART-III) with dimensions of 7.0 x $3.5 \mathrm{~mm}$ were prepared using a Teflon mould before determining micro-hardness and compressive strength. The cement was mixed according to the composition provided in Table 1, placed in the Teflon mould and then compressed for 20 minutes. All specimens were then removed from the moulds and stored at $100 \%$ relative humidity (Although not immersed) for $24 \mathrm{hrs}$. during maturation of the material.

\section{Micro-Hardness}

Ten samples each of ART-I, II and III materials were selected randomly for micro-hardness testing. Samples were polished by using emery papers of particle sizes varying from 01 to 03 before recording the micro-hardness. Their micro-hardness, measured as the Vickers Hardness Number (VHN), was recorded using a standard micro-hardness tester (HMV-G, Shimadzu).

The Vickers Hardness indentation was performed under a load of $100 \mathrm{~g}$ for a period of $15 \mathrm{~s}$ on the polished surface of the prepared samples. For each sample, 3 indentations were performed and the mean VHN value was recorded.

\section{Compressive Strength}

The remaining $\mathrm{n}=30$ samples, consisting of ten samples each of ART-I, II and III materials, were used for compressive strength testing. Each sample was loaded and compressed to the limit of distortion using a Tensometer 6907 mechanical testing facility.

The compressive strength was determined by dividing the value of failure-load of a specimen with the crosssectional area of the sample.

$\mathrm{CS}=\mathrm{P} / \pi \mathrm{r}^{2}$, where $\mathrm{CS}$ was the compressive strength in $\mathrm{MPa}, \mathrm{P}$ was the load in newtons and $\mathrm{r}$ was the radius of the specimen in millimetres.
Scanning Electron Microscopy (SEM) to explore the Marginal Adaptation of ART to Tooth Structure-

After acquiring Research Ethics Committee approval for the SEM study, a total of thirty caries-free extracted human teeth were selected randomly, cleansed and soaked in $0.5 \%(\mathrm{w} / \mathrm{v})$ ethanol-based chlorhexidine for 20 mins prior to being placed in distilled water ( $\mathrm{pH}$ 7.0) for a 7-day period. Using a cylindrical bur, standardised cavities were prepared, rinsed with distilled water and dried at ambient temperature. These 30 teeth were randomly sub-divided into three groupsGroups A, B and C. Freshly prepared ART-I material was placed in Group A teeth, ART-II material in Group B teeth and ART-III material in Group C teeth. The samples were cured at room temperature for $24 \mathrm{hrs}$., whilst stored in airtight sample containers. Following 24 hrs., samples were cut and polished using emery papers (the grit size was ranged from 1/0 to $3 / 0$ ). Samples were etched using 35\% (v/v) orthophosphoric acid for $15 \mathrm{~s}$ to remove the smear layer and etch the surface, washed with distilled water and then dried with tissue paper. The restored teeth were then dehydrated in a series of laboratory-grade aqueous-ethanol solutions [30\%, 40\%, $50 \%, 60 \%, 70 \%, 80 \%$ and then $90 \%(\mathrm{v} / \mathrm{v})$ absolute ethanol] for 10 mins. Samples were then placed in desiccators for 24 hrs.

After the samples were dried in an oven at $110^{\circ} \mathrm{C}$ for 15 mins, they were then gold sputter-coated before examination using a Scanning Electron Microscope (SEM) (model: JEOL JSM-6380LA). Areas were sub-divided into two sites (the coronal enamel-cement and root dentine-cement junctions), and marginal gap images of each sample were obtained from two sites. Magnification used was from X500 to X2500.

\section{Statistical Analysis}

Statistical analysis of the micro-hardness and compressive strength values was carried out using the SPSS version 20 software. One-Way ANOVA, Tukey's Highly Significant Difference (HSD) and Scheffe's tests were conducted to assess the level of significance of differences between mean values in post-hoc testings.

\section{RESULTS}

\section{Micro-Hardness}

The mean (SD) micro-hardness for ART materials are discussed in Table 2. Micro-hardness of ART decreases with increase in the percentage of Neem extract added to it [Figure-1].

\section{Compressive Strength}

Table 3 presents the compressive strength of ART materials. Compressive strength of ART is directly proportional to Neem extract quantity in the composition of it [Figure 2].

\section{SEM Study}

The mean (SD) marginal gap between the ART-I and enamel was $1.45 \pm 0.007$ (mean \pm SD) $\mu \mathrm{m}$, whilst that between the ART-I material and dentine was $1.31 \pm 0.003 \mu \mathrm{m}$ (Figure 4(a) and 4(b)). No marginal gap was found between the ART-II and either the enamel or dentine of the tooth (Figure 5(a) and 5(b)). However, there was an uneven marginal gap between the ART-III and tooth structure (Figure 6(a) and 6(b)). The mean marginal gap between ART-I and enamel was $9.87 \pm 1.03$ $\mu \mathrm{m}$ and that between ART-III and dentine was $10.97 \pm 0.96 \mu \mathrm{m}$ (Table 4). Marginal gap between ART and tooth structure 
decrease with increase in percentage of Neem extract added

to it [Figure 3].

\begin{tabular}{|c|c|c|c|c|}
\hline Composition of ART Material & ART-I (\%) & ART-II (\%) & ART-III (\%) & Action \\
\hline Zinc Oxide & 20 & 20 & 20 & Base of the Cement \\
\hline Aluminium Oxide & 70 & 70 & 70 & Base of the cement \\
\hline Hydrogenated rosin & 06 & 06 & 06 & Bonding Agent \\
\hline Sodium Fluoride (NaF) & 03 & 03 & 03 & Fluoride Agent \\
\hline Neem extract & 06 & 11.5 & 00 & Antibacterial Agent \\
\hline Eugenol & 40 & 40 & 40 & Binding Agent \\
\hline Ethoxybenzoic Acid (EBA) & 60 & 60 & 60 & Bonding Agent \\
\hline
\end{tabular}

\begin{tabular}{|c|c|c|c|c|c|c|c|c|c|}
\hline \multirow{2}{*}{ Material } & \multirow{2}{*}{$\mathbf{N}$} & \multicolumn{3}{|c|}{ Micro-Hardness (VHN) } & \multirow{2}{*}{ SD } & \multirow{2}{*}{ SE } & \multicolumn{3}{|c|}{ Statistical Analysis } \\
\hline & & Minimum & Maximum & Mean & & & ANOVA & Tukey HSD & Sheffe \\
\hline ART-I & 10 & 21.1 & 25.8 & 23 & 2.34734 & 1.04976 & \multirow{3}{*}{$\mathrm{p}<0.0001$} & \multirow{3}{*}{$\mathrm{p}<0.0001$} & \multirow{3}{*}{$\mathrm{p}<0.0001$} \\
\hline ART-II & 10 & 13.2 & 16.3 & 15.12 & 1.25976 & 0.56338 & & & \\
\hline ART-III & 10 & 35.3 & 36.4 & 35.72 & 0.42071 & 0.18815 & & & \\
\hline
\end{tabular}

Table 2. Vickers Hardness Number (VHN) of Three ART Materials. N- Total Number of Samples of each ART Materials, SDStandard Deviation, SE-Standard Error

\begin{tabular}{|c|c|c|c|c|c|c|c|c|c|}
\hline \multirow{2}{*}{ Material } & \multirow{2}{*}{$\mathbf{N}$} & \multicolumn{3}{|c|}{ Compressive Strength (MPa) } & \multirow{2}{*}{ SD } & \multirow{2}{*}{ SE } & \multicolumn{3}{|c|}{ Statistical Analysis } \\
\hline & & Minimum & Maximum & Mean & & & ANOVA & Tukey HSD & Sheffe \\
\hline ART-I & 10 & 38.2 & 56 & 45.88 & 5.46 & 1.72 & \multirow{3}{*}{$\mathrm{p}<0.0001$} & \multirow{3}{*}{\multicolumn{2}{|c|}{\begin{tabular}{|c|} 
High significant \\
differences in \\
compressive strength of \\
ART-III with ART-I and II
\end{tabular}}} \\
\hline ART-II & 10 & 43.3 & 61 & 50.06 & 6.14 & 1.94 & & & \\
\hline ART-III & 10 & 31.2 & 38.5 & 34.89 & 3.32 & 1.05 & & & \\
\hline
\end{tabular}

\begin{tabular}{|c|c|c|c|}
\hline \multirow[t]{2}{*}{ ART Material } & \multirow[t]{2}{*}{ Sample } & \multicolumn{2}{|c|}{$\begin{array}{l}\text { Mean (SD) Marginal Gap } \\
\text { (Micrometre) }\end{array}$} \\
\hline & & ART-Enamel & ART-Dentine \\
\hline ART-I & $\mathrm{n}=10$ & $1.45(0.007)$ & $1.31(0.003)$ \\
\hline ART-II & $\mathrm{n}=10$ & $0(0)$ & $0(0)$ \\
\hline ART-III & $\mathrm{n}=10$ & $9.87(1.028)$ & $10.97(0.964)$ \\
\hline
\end{tabular}

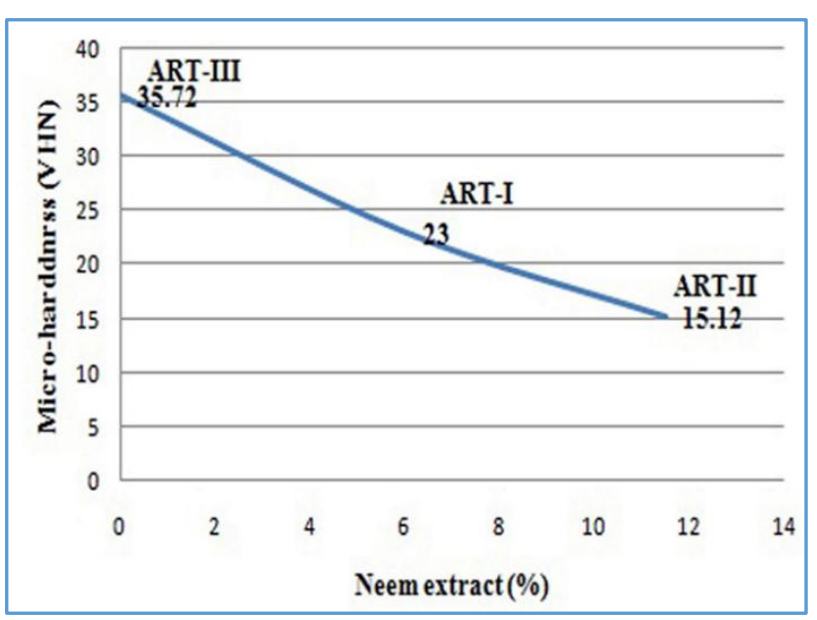

Figure 1. The Micro-Hardness of ART Materials is inversely proportional to the variation of Neem Extract (\%) added to the ART Materials

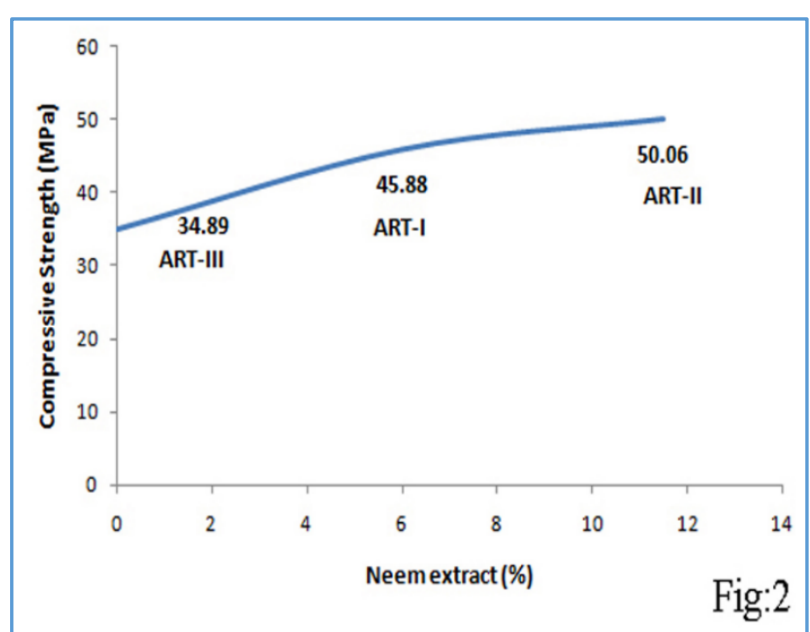

Figure 2. Shows the Compressive Strength (MPa) Value is proportional to Percentage of Neem Extract added to ART 


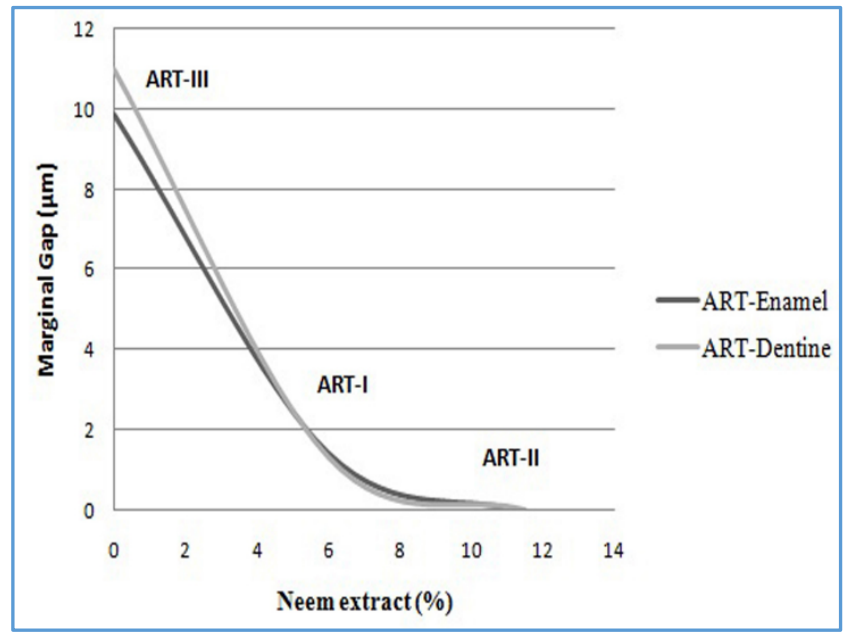

Figure 3. Representation of Variation of Marginal Integration between ART to Dental Structure vs Percentage of Neem Extract added to the Restorative Materials

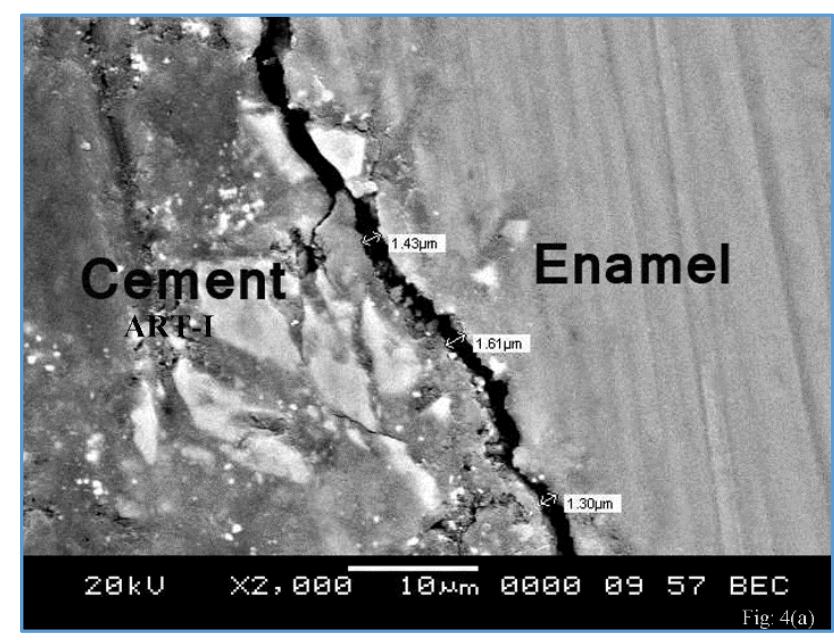

Figure 4(a). Shows a Marginal Gap between the Enamel and the ART-I with an Average Gap of 1.45 Micrometres

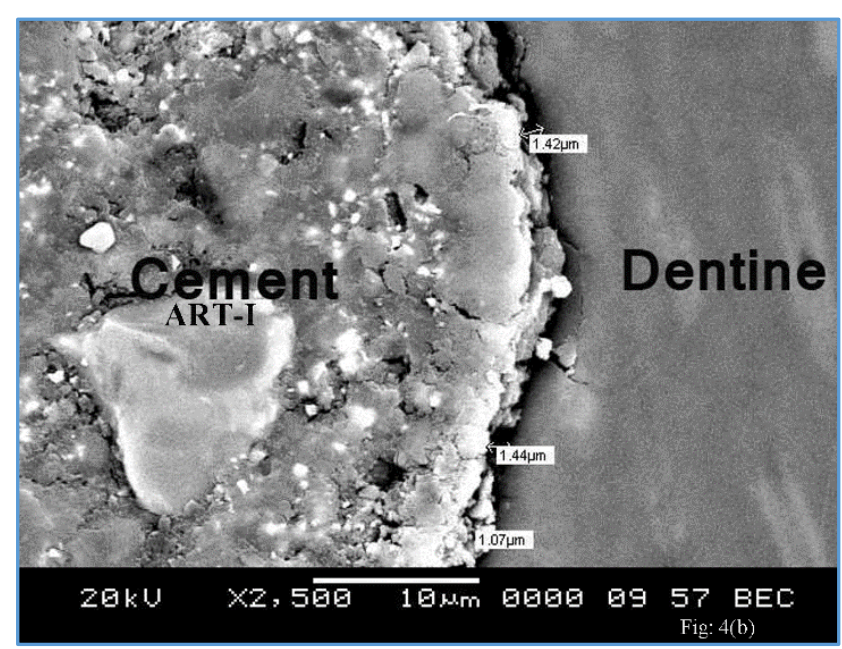

Figure 4(b). The Marginal Gap between Dentine to ART-I of an average 1.31 Micrometre

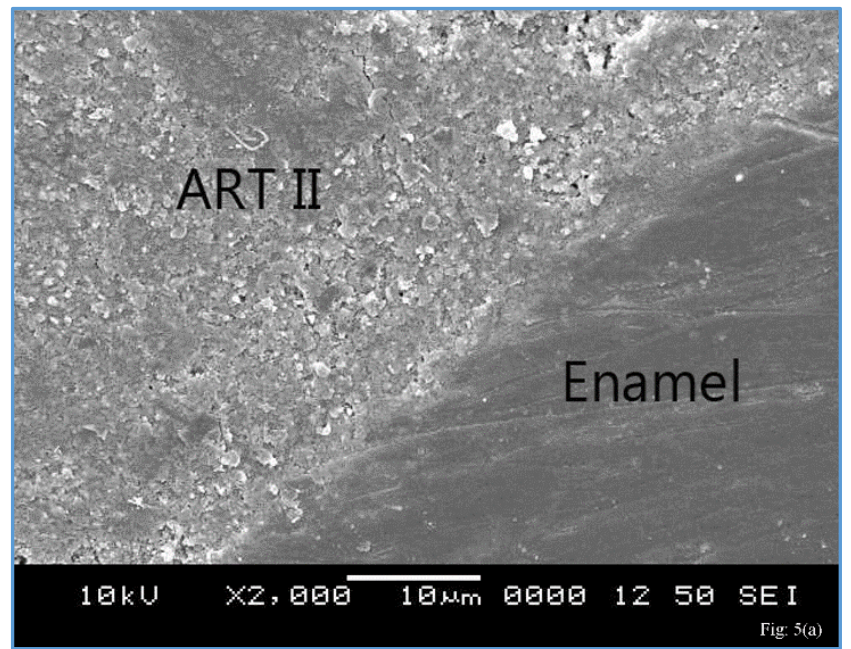

Figure 5(a). SEM Image shows no Marginal Gap between Enamel and ART-II Material

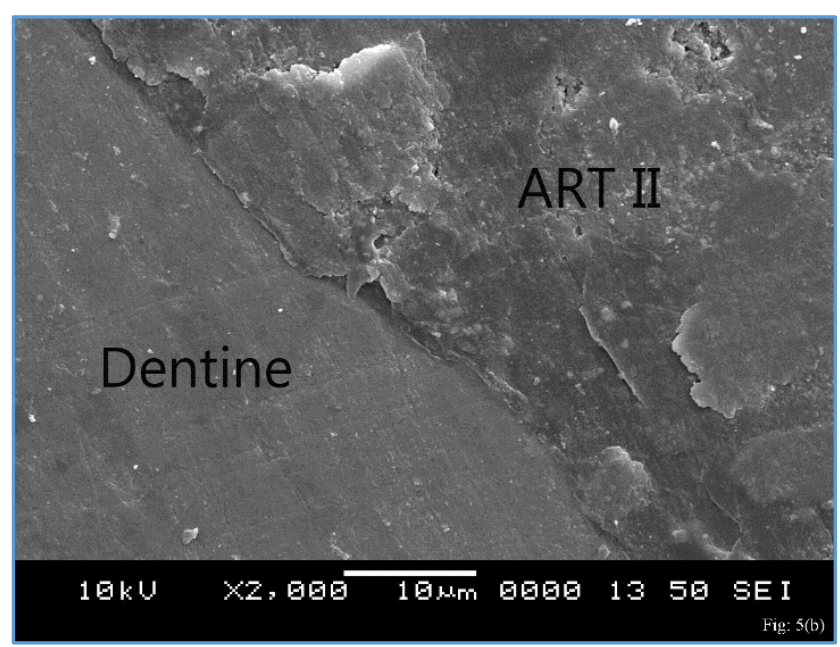

Figure 5(b). Shows a Good Adhesion between ART-II and Dentine

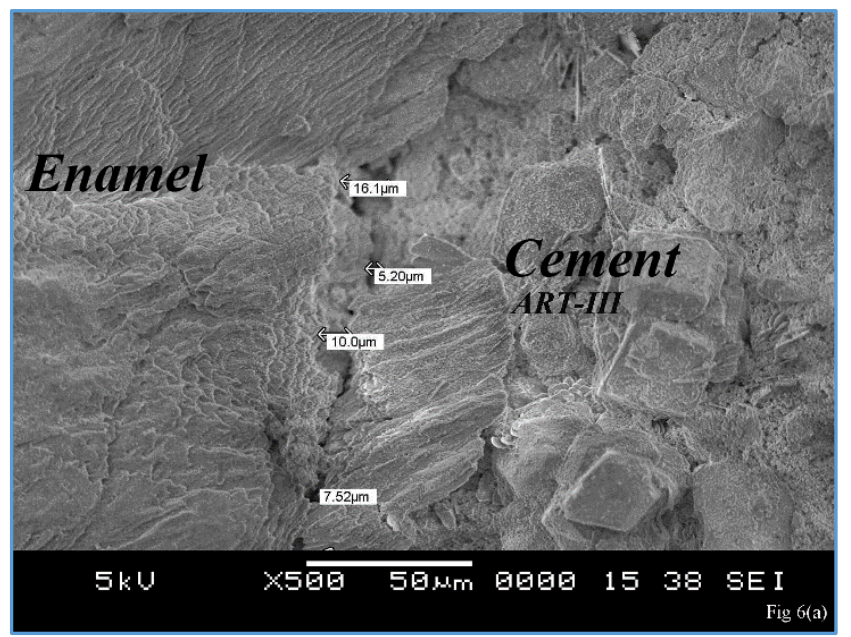

Figure 6(a). Shows the Irregular Marginal Gap between Tooth Enamel and ART-III 


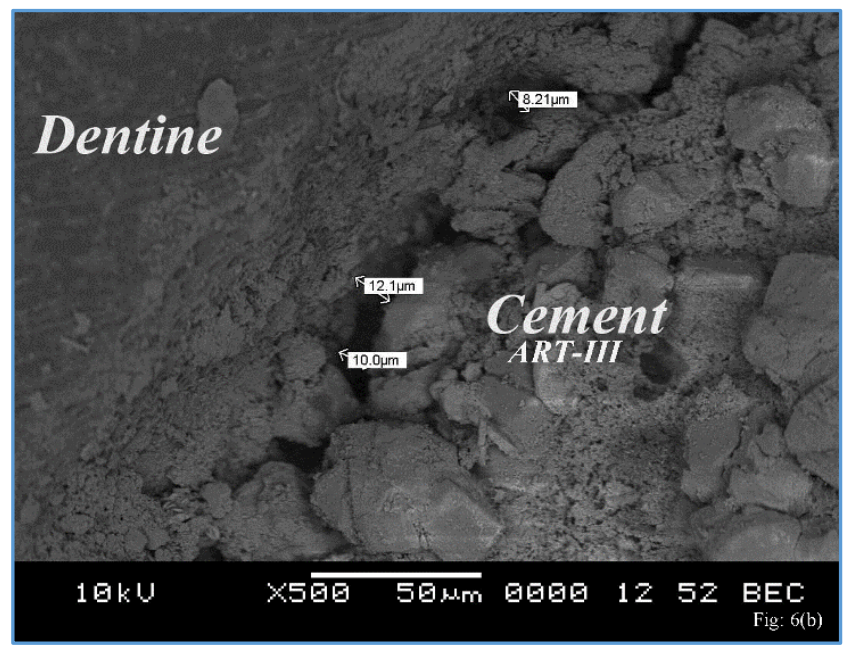

Figure 6(b). Shows the Irregular Marginal Gap between Root Dentine and ART-III

\section{DISCUSSION}

The development of new materials for ART applications are required to have an effective ability to bond to teeth, and this represented one of the major objectives of this study. Indeed, this investigation involved different approaches for the assessment of these new ART materials, which consisted of a basic powder containing zinc oxide, alumina and an acidic liquid of ethoxy benzoic acid and eugenol that are mixed together in a viscous paste. ${ }^{[19]}$ This then sets into a hardened mass [Table 1].

The criteria to choose of varying percent of Neem and that was based on antibacterial activity of Neem; therefore, in order to determine the maximum antibacterial activity we used different concentration of Neem extracts. The antibacterial efficiency of the new ART materials incorporated with Neem extract were assessed by measuring the zone of inhibition in the agar diffusion test (Data was not included in this study). We also ensure that the general physical properties of the ART material are not compromised with the concentration of the extract.

The setting time of ART-I and ART-II was 12.59 and 17 minutes respectively, while ART-III was hardened in 11 minutes. The setting time varies with the variation in the percentage of Neem extract added to the ART materials. Setting time was found to be proportional to the percentage of Neem present in the ART. Azadirachta indica commonly known as Neem which possesses anti-bacterial, anticarcinogenic, anti-helminthic, anti-diabetic, anti-oxidant, astringent, anti-viral, cytotoxic and anti-inflammatory activity. The chief active constituent of Neem is azadiracht, an effective antimicrobial agent.[20] Nimbidin, nimbin, nimbolide, Azadirachtin, gallic acid, epicatechin, catechin and margolone are the phytochemical constituents present in Neem extract are responsible for antibacterial activity.[21]

\section{Micro-Hardness}

Surface hardness is an important property that can relate to wear, abrasion resistance and durability of a material.[22] As the Vickers hardness increases, the surface hardness of the material also increases. However, several studies on hardness of restorative materials have been carried out using Knoop Hardness measurements.[23-25] Vicker's hardness has been used to assess the surface hardness of glass ionomer cements; other dental materials have been used elsewhere. [2632] Tüzüner $T$ and Ulusu $T$ in their study found that microhardness of one of the marketed ART (Fuji IX) was 53 VHN.[27]

In this study, the Vicker's hardness measurement showed highly significant differences for micro-hardness $(\mathrm{P}<0.0001)$ The micro-hardness of the ART-I material ranged between 21.1 VHN and 25.8 VHN. The micro-hardness of ART-II was between $13.2 \mathrm{VHN}$ and 16.3 VHN. The micro-hardness of ART-III was between $35.3 \mathrm{VHN}$ and $36.4 \mathrm{VHN}$ [Table 2 and Figure 1].

In this study, ART-III material had higher Vicker's hardness values compared to ART-I followed by ART-II. It has been suggested that this could be due to ART-III not containing any added antibacterial agent (i.e. Neem extract), with the Vicker's hardness values of the materials decreasing with the addition of antibacterial agent.[22,27,33] Microhardness of ART materials are inversely proportional to the percentage of antibacterial agent in the sample, which was observed in the present study too.[27]

\section{Compressive Strength}

Compressive strength is an important property of tooth restorative materials, which can help protect materials from masticatory forces.[34-36] Compressive strengths can vary depending on the mixing and placement methods as well as the conditions maintained during measurement. Bresciani $\mathrm{E}$ et al found that compressive strength of marketed ART (Bioglass R) was $99 \mathrm{MPa} .{ }^{[2]}$

In the present study, no significant difference $(P>0.05)$ in compressive strength was observed between ART-I and ARTII. A significant difference in compressive strength was recorded between ART-III and ART-I as well as between ARTIII and ART-II ( $\mathrm{P}<0.0001)$. The maximum and minimum compressive strengths of the ART-I material were $38.2 \mathrm{MPa}$ and $56 \mathrm{MPa}$ respectively and that of ART-II was $43.3 \mathrm{MPa}$ and $61 \mathrm{MPa}$. Additionally, the compressive strength of ART-III ranged from $31.2 \mathrm{MPa}$ to $38 \mathrm{MPa}$ [Table 3, Figure 2]. The compressive strength of ART-II was greater than both ART-I and ART-III.

It has previously been noted that the compressive strength of ART material reduces when antibacterial agents were added.[22] But in the present study, compressive strength (CS) of ART-II showed more CS compared to ART-I and ART-III. It was observed that the CS of ART materials increases with increase in percentage of Neem extract added.

\section{SEM Study}

Scanning Electron Microscopic (SEM) analysis of restorative materials and tooth cavity preparations can assess the properties of surface topography, interface adhesion and porosity.[24] Out of the three newly-developed ART materials, ART-II had a higher percentage of ethanolic Neem extract compared to ART-I followed by ART-III. It was observed from the SEM images 1 to 6 that the ART-II material exhibited a relatively smooth surface, whereas ART-I and III displayed structural variations best described as surface irregularities.

The SEM images [Figure 4(a), 4(b), 5(a), 5(b), 6(a) and $6(b)]$ display the adaptation of the restorative material to the cavity walls of the tooth. In the present study, we found no marginal gap between the ART-II material and the wall of the tooth cavity with a regular surface being observed [Figure 
5(a) and 5(b)]. Hence, the ART-II material presented excellent adaptation with tooth structure. Conversely, poor adaptation was found between the ART-I material and the tooth structure [Figure 4(a) and 4(b)]. An uneven marginal gap between the ART-III and the wall of the restored tooth cavity [Figure 6(a) and 6(b)] was also observed, which contrasts with the ART-II adhesion. In the present study, Neem extract was introduced into the ART materials in the form of gel. Hence, during material preparation it was observed that adhesion of ART materials increased proportionally with the percentage of Neem extract; a potentially promising property for enhancing bonding of material to the tooth superstructure.

The percentage incorporation of ethanolic Neem extract in ART-II was greater than in the ART-I and ART-III materials [Table 1]. It is conceivable that Neem extract may not only potentially act as an antibacterial agent, but also as a possible binding agent which could be the subject of future work. Smooth surfaces and margins reduce the risk of plaque accumulation, microleakage, sensitivity, staining, recurrent caries, gingival irritation and staining. ${ }^{[37-39]}$

The success of a dental restorative material depends on an appropriate marginal seal. In the current study, ART-II showed excellent marginal adaptation to the wall of tooth cavity compared to ART-I and ART-III.

With the limitation of present study, it is difficult to predict the exact antibacterial agent and its quantity present in the Neem extract added to ART materials. Further study need to be done to know what is the actual agent responsible for antibacterial property and their mechanism of action. Also, why the marginal integration of ART materials to tooth structure improved with increase in percentage of Neem extract added to materials.

\section{CONCLUSION}

ART-II material showed substantially superior marginal adaptation to the tooth structure and a greater compressive strength compared to ART-I and ART-III materials; therefore, it shows much promise as a potential restorative material which also compared to marked ART materials. This study presented novel material and constituents for potentially new ARTs, augmented with antibacterial natural products i.e. Neem. This approach clearly enhances key structural and mechanistic properties of ART materials, whilst incorporating an inexpensive natural product with antibacterial properties.

Within the limitations of the present study, we aimed to determine the physical properties of new ART material and compared them with the published data of marketed ART. Initial study and future research will be conducted by comparing a group containing commercially available ART.

\section{ACKNOWLEDGEMENTS}

- The physical properties research was carried out in the Department of Metallurgical and Material Engineering, National Institute of Technology of Karnataka (NITK), Surathkal, Mangalore, India. We duly acknowledge the help of the staff.

- Statistical analysis was supported by Professor Krishna Bhatt, Department of Statistics of KS Hegde Medical Academy (KSHEMA), Nitte University, Deralakatte, Mangalore, India.

\section{REFERENCES}

[1] Honkala E, Behbehani J, Ibricevic $H$, et al. The Atraumatic Restorative Treatment (ART) approach to restoring primary teeth in a standard dental clinic. Int J Paediatr Dent 2003;13(3):172-9.

[2] Bresciani E, Barata TdeJE, Fagundes TC, et al. Compressive and diametral tensile strength of glass ionomer cements. J Appl Oral Sci 2004;12(4):344-8.

[3] Kochhar GK, Srivastava N, Pandit IK, et al. An evaluation of different caries removal techniques in primary teeth: a comparative clinical study. J Clin Pediatr Dent 2011;36(1):5-9.

[4] Schriks MC, Van Amerongen WE. Atraumatic perspectives of ART: psychological and physiological aspects of treatment with and without rotary instruments. Community Dent Oral Epidemiol 2003;31(1):15-20.

[5] Smales RJ, Yip HK. The Atraumatic Restorative Treatment (ART) approach for primary teeth: review of literature. Pediatr Dent 2000;22(4):294-8.

[6] Bonifácio CC, Kleverlaan CJ, Raggio DP, et al. Physical-mechanical properties of glass ionomer cements indicated for atraumatic restorative treatment. Aust Dent J 2009;54(3):233-7.

[7] Naoum S, Martin E, Ellakwa A. Long-term fluoride exchanges at restoration surfaces and effects on surface mechanical properties. Article ID 579039, ISRN Dent 2013;2013: p. 8 . http://dx.doi.org/10.1155/2013/579039

[8] Frencken JE, Holmgren CJ. How effective is ART in the management of dental caries? Community Dent Oral Epidemiol 1999;27(6):423-30.

[9] Ersin NK, Candan U, Aykut A, et al. A clinical evaluation of resin-based composite and glass ionomer cement restorations placed in primary teeth using the ART approach: results at 24 months. J Am Dent Assoc 2006;137(11):1529-36.

[10] Tay WM, Lynch E. Glass-ionomer (Polyalkenoate) cements - Part 1. Development, setting reaction, structure and types. J Ir Dent Assoc 1989a;35(2):53-7.

[11] Tay WM, Lynch E. Glass-ionomer cements - Part 2. Clinical properties I. J Ir Dent Assoc 1989b;35:59-64.

[12] Lynch E, Tay WM. Glass-ionomer cements - Part 3. Clinical properties II. J Ir Dent Assoc 1989;35:66-7.

[13] Lynch E, Tay WM. Glass-ionomer cements - Part 4. Clinical properties III. J Ir Dent Assoc 1989;35:75-82.

[14] Tay WM, Lynch E. Glass-ionomer cements - clinical usage and experience: 1. Dent Update 1990;17:11-6.

[15] Tay WM, Lynch E. Glass-ionomer cements - clinical usage and experience: 2. Dent Update 1990;17(2):516.

[16] Yap AU, Cheang PH, Chay PL. Mechanical properties of two restorative reinforced glass-ionomer cements. J Oral Rehabil 2002;29(7):682-8.

[17] Gladys S, Van Meerbeek B, Braem M, et al. Comparative physico-mechanical characterization of new hybrid restorative materials with conventional glass-ionomer and resin composite restorative materials. J Dent Res 1997;76(4):883-94. 
[18] Verma SJ, Gohil MH. Scanning electron microscopy study to analyse the morphological characteristics of root surfaces after application of Carisolv gel in association with scaling and root planning: In vitro study. J Indian Soc Periodontol 2012;16(3):329-32.

[19] Anusavice KJ, Shen C, Rawls HR, et al. "Dental Cements." Phillips' science of dental materials. 12th edn. St. Louis, Mo: Elsevier Health Sciences 2013: p. 303-39.

[20] Siswomihardjo W, Badawi SS, Nishimura M, et al. The difference of antibacterial effect of Neem leaves and stick extracts. Int Chin J Dent 2007;7:27-9.

[21] Lakshmi T, Krishna V, Rajendran R, et al. Azadirachta indica: a herbal panacea in dentistry - an update. Pharmacogn Rev 2015;9(17):41-4.

[22] Tuzuner T, Kuşgöz A, Er K, et al. Antibacterial activity and physical properties of conventional glass-ionomer cements containing chlorhexidine diacetate/cetrimide mixtures. J Esthet Restor Dent 2011;23(1):46-55.

[23] Zanata RL, Magalhaes AC, Lauris JR, et al. Microhardness and chemical analysis of high-viscous glass-ionomer cement after 10 years of clinical service as ART restorations. J Dent 2011;39(12):834-40.

[24] Xie D, Brantley WA, Culbertson BM, et al. Mechanical properties and microstructures of glass-ionomer cements. Dent Mater 2000;16(2):129-38.

[25] Itskovich R, Lewinstein I, Zilberman U. The Influence of Zinc Oxide Eugenol (ZOE) and Glass Ionomer (GI) base materials on the microhardness of various composite and GI restorative materials. Open Dent J 2014;8:13-9.

[26] Palma-Dibb RG, Palma AE, Matson E, et al. Microhardness of esthetic restorative materials at different depths. Mater Res 2003;6(1):85-90.

[27] Tüzüner T \& Ulusu T. Effect of antibacterial agents on the surface hardness of a conventional glass-ionomer cement. J Appl Oral Sci 2012;20(1):45-9.

[28] Silva KG, Pedrini D, Delbem AC, et al. Microhardness and fluoride release of restorative materials in different storage media. Braz Dent J 2007;18(4):30913.

[29] Baloch FA, Mirza AJ, Baloch D. An in-vitro study to compare the microhardness of glass ionomer cement set conventionally versus set under ultrasonic waves. Int J Health Sci (Qassim) 2010;4(2):149-55.
[30] Okada K, Tosaki S, Hirota K, et al. Surface hardness change of restorative filling materials stored in saliva. Dent Mater 2001;17(1):34-9.

[31] Cattani-Lorente MA, Dupuis V, Moya F, et al. Comparative study of the physical properties of a polyacid-modified composite resin and a resinmodified glass ionomer cement. Dent Mater 1999;15(1):21-32.

[32] Cattani-Lorente MA, Dupuis V, Payan J, et al. Effect of water on the physical properties of resin-modified glass ionomer cements. Dent Mater 1999;15(1):71-8.

[33] Türkün LS, Türkün M, Ertugrul $F$, et al. Long-term antibacterial effects and physical properties of a chlorhexidine-containing glass ionomer cement. Journal of Esthetic and Restorative Dentistry 2008;20(1):29-44.

[34] Chandana PS, Munaga S, Reddy MN, et al. Evaluation of compressive strength for a combination of glass ionomer cement and antibiotics. J Orofac Res 2013;3(4):245-8.

[35] Yesilyurt C, Er K, Tasdemir T, et al. Antibacterial activity and physical properties of glass-ionomer cements containing antibiotics. Oper Dent 2009;34(1):18-23.

[36] Busanello L, Telles M, Junior WGM, et al. Compressive strength of glass ionomer cements used for atraumatic restorative treatment. Revista Odonto Ciência 2009;24(3):295-8.

[37] Hossam AE, Rafi AT, Ahmed AS, et al. Surface topography of composite restorative materials following ultrasonic scaling and its Impact on bacterial plaque accumulation. An in-vitro SEM study. J Int Oral Health 2013;5(3):13-9.

[38] Say CE, Yurdagüven H, Yaman BC, et al. Surface roughness and morphology of resin composites polished with two-step polishing systems. Dent Mater J 2014;33(3):332-42.

[39] Taylor MJ, Lynch E. Microleakage. J Dent 1992;20(1):310. 